\title{
OCORRÊNCIA DE Pestalotiopsis psidii E Lasiodiplodia theobromae CAUSANDO PODRIDÃO NO CAULE DA GOIABEIRA NO CEARÁ
}

\author{
JOSÉ E. CARDOSO ${ }^{1}$, CLAUDIO B. MAIA ${ }^{1}$ \& MARIA N. G. PESSOA ${ }^{2}$ \\ ${ }^{1}$ Embrapa Agroindústria Tropical, Cx. Postal 3761, CEP 60060-510, Fortaleza,CE, fax (085) 299-1854, \\ e-mail: emilson@cnpat.embrapa.br; ${ }^{2}$ Universidade Federal do Ceará, Departamento de. Fitotecnia, \\ Cx. Postal 12.168, CEP 60356-001, Fortaleza, CE
}

(Aceito para publicação em 18/02/2002)

Autor para correspondência: José E. Cardoso

\section{ABSTRACT \\ Occurrence of Pestalotiopsis psidii and Lasiodiplodia theobromae causing stem rot of guava plants in the State of Ceará, Brazil}

A severe occurrence of stem rot of guava (Psidium guajava) was described for the first time in the State of Ceará, Brazil. This disease affects initially young plants at grafting points. Two fungi were associated with the disease: Pestalotiopsis psidii and Lasiodiplodia theobromae.
Goiabeiras (Psidium guajava L.) recém transplantadas em um pomar 0,5 ha na Estação Experimental do CuruParaipaba da Embrapa Agroindústria Tropical, Paraipaba, CE foram acometidas de uma doença caracterizada por sintomas de podridão seca do caule. Esta anormalidade foi observada, recentemente, em 40\% das mudas (cultivares Rica e Ogawa). Amostras das mudas doentes foram introduzidas no Laboratório de Fitopatologia da Embrapa Agroindústria Tropical para análise dos sintomas e sinais. Procedeu-se o isolamento dos possíveis agentes causais a partir dos tecidos lesionados e das estruturas de frutificação fúngica.

Os possíveis patógenos foram isolados e identificados considerando-se os aspectos morfológicos da colônia em ágar e a morfologia das estruturas de frutificação, observada sob microscópio ótico, com o auxílio de ilustrações e chaves taxonômicas. Foram isolados e identificados os fungos Pestalotiopsis psidii (Pat.)Venk. e Lasiodiplodia theobromae (Pat.) Griff. Os testes de patogenicidade, realizados em mudas de quatro meses da cv. Rica, constaram da introdução de discos de batata dextrose ágar (BDA) $(0,5 \mathrm{~cm}$ de diâmetro) colonizados com os respectivos fungos inoculados sobre a superfície do tecido hospedeiro perfurado com estilete esterilizado. A região inoculada foi coberta com "parafilm" por $48 \mathrm{~h}$. O ensaio constou de quatro tratamentos (dois isolados, inoculados individualmente e em conjunto e a testemunha) com três plantas por tratamento, com quatro repetições. A avaliação foi feita 15 dias após a inoculação, observando-se os sintomas e sinais e anotando-se o comprimento da lesão no caule de cada planta.

As observações da doença em campo sugerem que o processo de infecção se inicia a partir do ponto de enxertia, uma vez que o porta-enxerto não apresentou, em nenhum caso, sintomas da anormalidade. O caule afetado apresentavase com manchas necróticas deprimidas de aproximadamente $10 \mathrm{~cm}$ de comprimento, coloração marrom claro, cobrindo toda a epiderme do caule e ramos do hospedeiro. Essas manchas estendiam-se no sentido ascendente a partir do ponto de provável infecção do caule da planta. Posteriormente, os sintomas tornavam-se mais severos, assumindo uma coloração esbranquiçada, permitindo a visualização, a olho nu, de pontos escuros em toda a sua superfície, característicos de estruturas de frutificação fúngica, as quais foram identificadas sob estereoscópio como sendo acérvulos.

Os resultados revelaram-se positivos nas plantas inoculadas com os patógenos, sendo, entretanto, individualmente, $P$. psidii mais virulento que $L$. theobromae (comprimento da lesão: $2,16 \mathrm{~cm}$ e 1,60 cm, respectivamente). Tecidos inoculados com ambos os patógenos apresentaram um comprimento médio de lesão $(5,30 \mathrm{~cm})$ maior que qualquer um deles, individualmente. Em todos os casos, foram observados os sintomas característicos daqueles, inicialmente, descritos sob as condições de campo, inclusive com intensa esporulação sobre os tecidos afetados a partir dos quais foram reisolados ambos os patógenos.

Embora detectado nessa cultura causando doença em frutos na China (Tsay, Plant Protection Bulletin 33:384-394, 1991) e em caule na Índia (Kaushik et al. Indian Phytopathology 25:61-64, 1972), desconhece-se, até o presente, qualquer referência relativa à ocorrência de $P$. psidii sobre este hospedeiro no Ceará. Este é o primeiro relato da manifestação deste patógeno em goiabeira no Brasil. 